\title{
Solidification behavior and thermal conductivity of bulk sodium acetate trihydrate composites with thickening agents and graphite
}

\author{
Dannemand, Mark; Johansen, Jakob Berg; Furbo, Simon
}

Published in:

Solar Energy Materials and Solar Cells

Link to article, DOI:

10.1016/j.solmat.2015.10.038

Publication date:

2016

Document Version

Peer reviewed version

Link back to DTU Orbit

Citation $(A P A)$ :

Dannemand, M., Johansen, J. B., \& Furbo, S. (2016). Solidification behavior and thermal conductivity of bulk sodium acetate trihydrate composites with thickening agents and graphite. Solar Energy Materials and Solar Cells, 145, 287-295. https://doi.org/10.1016/j.solmat.2015.10.038

\section{General rights}

Copyright and moral rights for the publications made accessible in the public portal are retained by the authors and/or other copyright owners and it is a condition of accessing publications that users recognise and abide by the legal requirements associated with these rights.

- Users may download and print one copy of any publication from the public portal for the purpose of private study or research.

- You may not further distribute the material or use it for any profit-making activity or commercial gain

- You may freely distribute the URL identifying the publication in the public portal 


\title{
Solidification Behavior and Thermal Conductivity of Bulk Sodium Acetate Trihydrate Composites with Thickening Agents and Graphite
}

\author{
Mark Dannemand*, Jakob Berg Johansen, Simon Furbo \\ Technical University of Denmark, Department of Civil Engineering, Kgs. Lyngby, 2800, \\ Denmark \\ *Corresponding email: markd@byg.dtu.dk
}

Keywords: Phase Change Material, Sodium Acetate Trihydrate, Solidification, Thermal Conductivity, Supercooling, thickening agent.

\section{SUMMARY}

Sodium acetate trihydrate is a promising phase change material for long term storage of solar thermal energy if supercooling is actively utilized. Well performing thermal energy storages need to be able to charge and discharge energy at a high rate. The relatively low thermal conductivity of the phase change material limits the heat exchange capacity rate to and from the storage. Another factor that limits the heat transfer is the contraction and expansion of the salt hydrate during the phase change. This density change causes formation of cavities inside the solid storage material. Investigations of the solidification behavior, the formation of cavities and thermal conductivity of composites based on sodium acetate trihydrate crystalizing with or without supercooling are presented in this paper. The thermal conductivity was measured with an ISOMET hot disc surface measurement probe. Samples that crystalized without supercooling tended to form solid crystals near the heat transfer surface and cavities away from the heat transfer surface. The measured thermal conductivity was up to $0.7 \mathrm{~W} / \mathrm{m} \mathrm{K}$ in solid sodium acetate trihydrate. Samples that crystalized from supercooled state formed fewer large cavities but had a lower thermal conductivity. A composite with sodium acetate trihydrate, thickening agent and 5\% graphite flakes had a thermal conductivity of up to $1.1 \mathrm{~W} / \mathrm{m} \mathrm{K}$.

\section{INTRODUCTION}

The phase change material (PCM) sodium acetate trihydrate (SAT) is a promising material for heat storages. It has a relatively high latent heat of fusion of $264 \mathrm{~kJ} / \mathrm{kg}$ at a melting point of 58 ${ }^{\circ} \mathrm{C}$ [1]. This melting point makes it suitable for applications for space heating and domestic hot water preparation combined with solar thermal energy [2]. SAT has the ability to supercool in a stable way down to ambient temperature and is therefore a candidate material for long term heat storage. Long term or seasonal heat storage is possible by melting SAT by solar energy and then letting it remain in supercooled state at ambient temperature in the storage period [3]. Once the crystallization of the supercooled SAT is initialized, the latent heat of fusion is released and can be discharged for heating purposes. Dannemand et al. describe a number of barriers and solutions for operating a seasonal heat storage based on stable supercooling of SAT as well as some numerical calculations elucidating the potential [4]. One of the limiting factors in using PCMs in a heat storage is the low thermal conductivity of the PCM itself, which limits the heat exchange capacity rate and discharge power of the storage [5].

The enhancement of the thermal conductivity of PCMs has been investigated by several researchers. One method is to create PCM composites with enhanced thermal properties by 
mixing additives in the PCM. Another method is to have fixed highly conductive structures or fins inside the PCM storage or to impregnate a highly conductive porous media with the PCM. Li et al. investigated the effect of adding powdered expanded graphite (EG) into SAT and found that the thermal conductivity could be almost doubled by adding $10 \%$ EG to the SAT mixture, which also contained Carboxymethyl cellulose (CMC) [6]. Lee et al. investigated composites of EG and erythritol and found that EG as an additive is a highly promising material for improving heat transfer in heat storages with PCMs [7]. Cabeza et al. studied the effect of adding steel pipes or copper pieces as fins in a storage with water as PCM to increase heat transfer, but found that a graphite matrix was better [8]. Sari and Karaipekli showed that the thermal conductivity of a paraffin could be increased significantly by adding a few percentage of EG and this would decrease the melting time of the PCM [9]. Mills et al. also showed that the thermal conductivity of a graphite matrix impregnated with PCM is a viable choice for enhancing thermal conductivity [10]. Also Py et al. showed that paraffin impregnated in compressed expanded natural graphite significantly increased the thermal conductivity compared to the paraffin alone [11]. Zhang and Fang carried out investigations on paraffin and EG composites and likewise found this an effective way of increasing thermal conductivity [12]. Fan and Khodadadi did a review on thermal conductivity enhancement of PCMs for thermal energy storage [13]. Jegadheeswaran and Pohekar did a review on several other techniques for enhancing the performance of latent heat storages [5]. Kousksou et al. also did a review listing some important characteristics of energy storage including latent heat storages with salt hydrates [14]. Considering a storage with stable supercooling of SAT, Johansen et al. had SAT samples mixed with graphite powder in stable supercooled condition for five months after it had been heated to $85^{\circ} \mathrm{C}$ for 12 hours [15]. They concluded that it is possible to have stable supercooled composites of SAT and graphite powder at ambient temperature.

\subsection{Phase separation and additives}

SAT is an incongruently melting salt hydrate and suffers from phase separation especially over repeated melting and solidification cycles [16]. The problem has been sought to be solved by adding extra water [17] or thickening agents to the SAT. Ramirez et al. studied the use of CMC and silica gel to avoid phase separation of SAT and reported thermal cycling stability in cycles from $30^{\circ} \mathrm{C}$ to $72{ }^{\circ} \mathrm{C}$ by use of differential scanning calorimetry (DSC) [18]. $\mathrm{Hu}$ et al. investigated the reduction of supercooling by the use of Aluminium Nitride nanoparticles in the SAT composite with 4\% CMC and found the thickening agent suitable to avoid phase separation and suspend the nucleation agent in the mixture [19]. Ryu et al. investigated several salt hydrates and found that for some salt hydrates a super absorbent polymer (SAP) was an effective thickening agent however CMC was more effective for SAT [20]. Shin et al. investigated the combination of CMC and expanded graphite as additives for SAT and found that composites with $2.5 \mathrm{wt} \% \mathrm{EG}$ and $5 \mathrm{wt} \% \mathrm{CMC}$ had a thermal conductivity of $1.85 \mathrm{~W} / \mathrm{m} \mathrm{K}$ [21]. Meisingset and Grønvold investigated thermodynamic properties of salt hydrates and suggested that $0.5 \%$ to $1 \%$ xanthan rubber can solve the problem of phase separation in SAT [22]. A suitable thickening agent could both solve phase separation and keep small sized conduction enhancers evenly distributed in the PCM composite at the temperature the storage is meant to operate at and over its lifetime.

\subsection{Solidification}

The density difference between the solid and liquid SAT is approximately $10 \%$ [23]. The resulting volume change of the PCM in a rigid storage tank will cause formation of cavities [24]. These cavities act as thermal resistances, reducing the effective thermal conductivity of the bulk PCM. This was also reported by Choi et al., who investigated heat transfer in 
storages with SAT [25]. Once a supercooled PCM is nucleated, it crystalizes almost instantly [26]. A PCM that solidifies without supercooling crystalizes at a slower rate as the crystallization front moves with the heat being released and the temperature drops below the melting point. Whether the PCM solidifies without supercooling or with a high degree of supercooling may affect the formation of the solid PCM and the location of the cavities, which affect the thermal conductivity of the bulk PCM. Additives such as extra water and thickening agents added to avoid phase separation may also affect the thermal conductivity of the PCM.

\subsection{Applications}

In designing and planning thermal systems including heat storages, numerical simulation models are an important tool. To do numerical calculations of PCM storages, an accurate value for the thermal conductivity of the PCM in bulk sizes that resemble the usage in full scale applications is desired. Lele et al. found the importance of investigating the effective thermal conductivity of the storage material using a measuring setup representative of the considered application [27]. They found that a self-made guarded hot cartridge method gave results more representative for the real storage compared to DSC measurements.

Literature values for the thermal conductivity of solid SAT range from $0.17 \mathrm{~W} / \mathrm{m} \mathrm{K}$ [21] to $0.7 \mathrm{~W} / \mathrm{m} \mathrm{K}$ [28][29]. In previous literature there was no distinction between the thermal conductivity of SAT composites crystalizing from supercooled state or without supercooling.

This article reports the investigations by a simple suspension test on how well different concentrations of the thickening agents CMC and xanthan rubber suspend graphite particles in SAT composites. The second part of this article reports on the solidification behavior and the formation of cavities. Additionally, the thermal conductivity in bulk size SAT composites, which are meant to resemble the conditions in an actual heat storage with or without utilizing supercooling, were investigated. Measurements showed how extra water, thickening agents and graphite powder or graphite flakes affected the thermal conductivity of bulk size PCM composites.

\section{METHOD}

Sodium acetate trihydrate was purchased from the company IG Chemicals GmbH. Carboxymethyl cellulose and xanthan rubber was received as samples from the company CP Kelco under the product names Cekol 30.000 and Keltrol Advanced performance-F. Fine graphite powder with a particle size less than $50 \mu \mathrm{m}$ and graphite flakes mesh size 10 (see Figure 1) were purchased from the company VWR International.

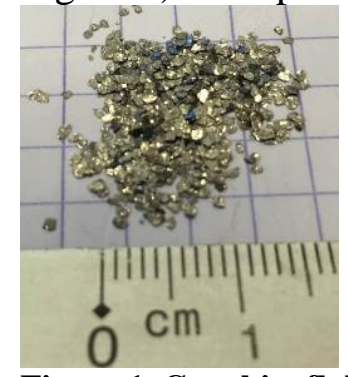

Figure 1. Graphite flakes mesh size 10.

\subsection{Suspension of graphite in PCM mixture}

To ensure a PCM composite with graphite uniformly distributed in the sample simple suspension tests were carried out. The aim was to investigate the ability of the thickening 
agents to suspend the graphite in the PCM composite at a temperature of $90{ }^{\circ} \mathrm{C}$ which could be the maximum operating temperature of a PCM storage with SAT in a solar combi system. Graphite powder and flakes have a higher density than SAT. The graphite will separate from the PCM and settle to the bottom of the container if no precautions are taken. Mixtures of 200 g SAT with $1 \%, 2.5 \%$ and 5\% CMC and SAT with $0.25 \%, 0.5 \%$ and $1 \%$ xanthan rubber (all weight \%) were prepared without graphite. Then a layer of $40 \mathrm{~g}$ graphite powder or graphite flakes mixed with SAT in the ratio 1:10 was placed on top of the thickened PCM mixture. The samples were heated in an oven to $90^{\circ} \mathrm{C}$ for 14 days. During this period the samples inspected to see if the graphite settled to the bottom of the sample or remained suspended on the top of the sample. It was assumed that if the graphite stayed suspended on the top of the sample, the viscosity of the thickened PCM mixture would also be high enough to keep a uniform composite. On the other hand, if the graphite would fall through the thickened PCM mixture during the test period, it would also eventually settle to the bottom of a container in an application intended to function for years. In this case the graphite would not give the desired effect of increasing the thermal conductivity in the entire bulk.

Shaking the samples would also affect the mixing, therefore the sample were carefully handled when being inspected.

\subsection{Solidification and thermal conductivity sample preparation}

To evaluate the thermal conductivity and the formation of cavities in PCM composites based on SAT in bulk size, a series of $1.3 \mathrm{~kg}$ samples were prepared in glass jars with airtight lids (see Figure 2). The PCM samples were 90 to $100 \mathrm{~mm}$ high and had a diameter of $120 \mathrm{~mm}$.

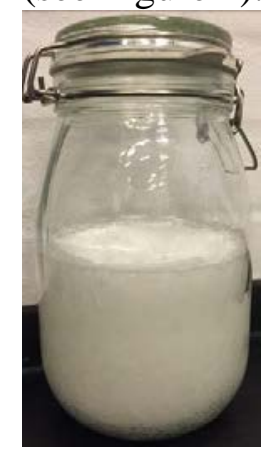

Figure 2. 1.3 kg PCM composite based on SAT in glass jar.

To elucidate the different behavior of samples that crystalized from supercooled state or with minimal supercooling, two of each PCM composites were prepared. For most of the samples multiple repetitions were made to confirm repeatability. The following types of PCM composites were prepared.

1) Sodium acetate trihydrate

2) Sodium acetate trihydrate plus $9 \%$ extra water

3) Sodium acetate trihydrate plus $0.5 \%$ xanthan rubber

4) Sodium acetate trihydrate plus $0.5 \%$ xanthan rubber and $5 \%$ graphite powder

5) Sodium acetate trihydrate plus $1 \%$ xanthan rubber and $5 \%$ graphite flakes

6) Sodium acetate trihydrate plus 1\% CMC

7) Sodium acetate trihydrate plus 1\% CMC and $2 \%$ graphite powder

The PCM composites were prepared by melting the SAT in an oven at $90{ }^{\circ} \mathrm{C}$ for 24 hours in the closed glass jars. For samples with graphite, the graphite was mixed into the SAT before placing in the oven. For samples with CMC, the thickening agent was added to the melted SAT while stirring with an overhead mixer until a uniform mixture was achieved. For 
samples thickened with xanthan rubber, the thickening agent was mixed with $130 \mathrm{~g}$ of the SAT in crushed solid state at ambient temperature. The xanthan rubber and SAT mixture was then added to the melted SAT little by little while stirring with an overhead mixer to ensure a uniform mixture. At temperatures around $90{ }^{\circ} \mathrm{C}$ the SAT composite with xanthan rubber became a thick jelly that easily trapped air bubbles. It was therefore necessary to stir the PCM composite carefully to avoid trapping air bubbles in the PCM. After adding the additives, the samples were placed in the oven for 4 hours to obtain a uniform temperature, before they were removed from the oven and placed in the ambient at a temperature of about $22{ }^{\circ} \mathrm{C}$.

One of each sample type was set to cool in the closed glass jar to ambient temperature for 24 hours. This left the samples in supercooled state after which the crystallization was started by opening the jar and adding a seed crystal of SAT. In other samples of each type the lid was opened as they cooled down and the temperatures of the samples were monitored. As the temperature of the sample dropped close to the melting temperature of $58^{\circ} \mathrm{C}$, a seed crystal was added to ensure crystallization without supercooling. This passive cooling and crystallization without supercooling is referred to as natural cooling in this article. The samples reached ambient temperature approximately 24 hours after crystallization was started. One heating and cooling cycle for each sample was carried out over 48 to 72 hours. After the samples were crystalized and cooled to ambient temperature, the samples were removed from the jars. The samples were cut horizontally at approximately $1 / 3$ and $2 / 3$ of their height, as indicated in Figure 3. Each layer of the samples had a thickness of 25-30 mm. The solidification behavior and the formation of cavities in each layer of the samples were inspected visually and measurements of thermal conductivity were carried out.

Top

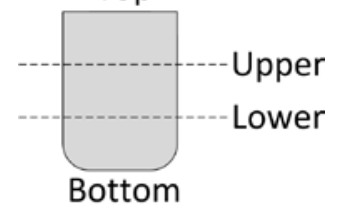

Figure 3. Cut in PCM sample

\subsection{Measuring procedure}

Measurements of the thermal conductivity at top and bottom as well as on the surface of the cut layers of the samples were carried out with an ISOMET model 2104 Heat Transfer Analyser from Applied Precision Ltd. The accuracy of the thermal conductivity measurements are stated to be $5 \%$ for values up to $0.7 \mathrm{~W} / \mathrm{m} \mathrm{K}$ and $10 \%$ for values above 0.7 $\mathrm{W} / \mathrm{m} \mathrm{K}$ [30]. The tool utilizes the hot disc principle, so the thermal conductivity of the sample was measured at the surface. The tool requires a flat surface with at least the same diameter as the probe of $60 \mathrm{~mm}$ and a minimal thickness of the material of 10-15 mm. Before the measurements were carried out, the surfaces of the samples were made level with sandpaper to ensure a good thermal contact between the probe and the sample. The measurements were made in the center of the samples or where it was possible to place the probe on a uniform surface without too large cavities. The measurements were repeated 2-5 times with slight offsets between each measurement. Averages of these measurements are presented in the result chapter.

\section{RESULTS AND DISCUSSION}

\subsection{Suspension of graphite in the PCM mixture}

Pictures of the samples from before starting the suspension test and after being in the oven at $90{ }^{\circ} \mathrm{C}$ at selected time intervals are shown in Table 1 and Table 2 . The samples were inspected to observe the suspension of the graphite. 
Table 1. Samples of SAT with $1 \%$, $2.5 \%$ and $5 \%$ CMC from left to right with graphite SAT mix on top.

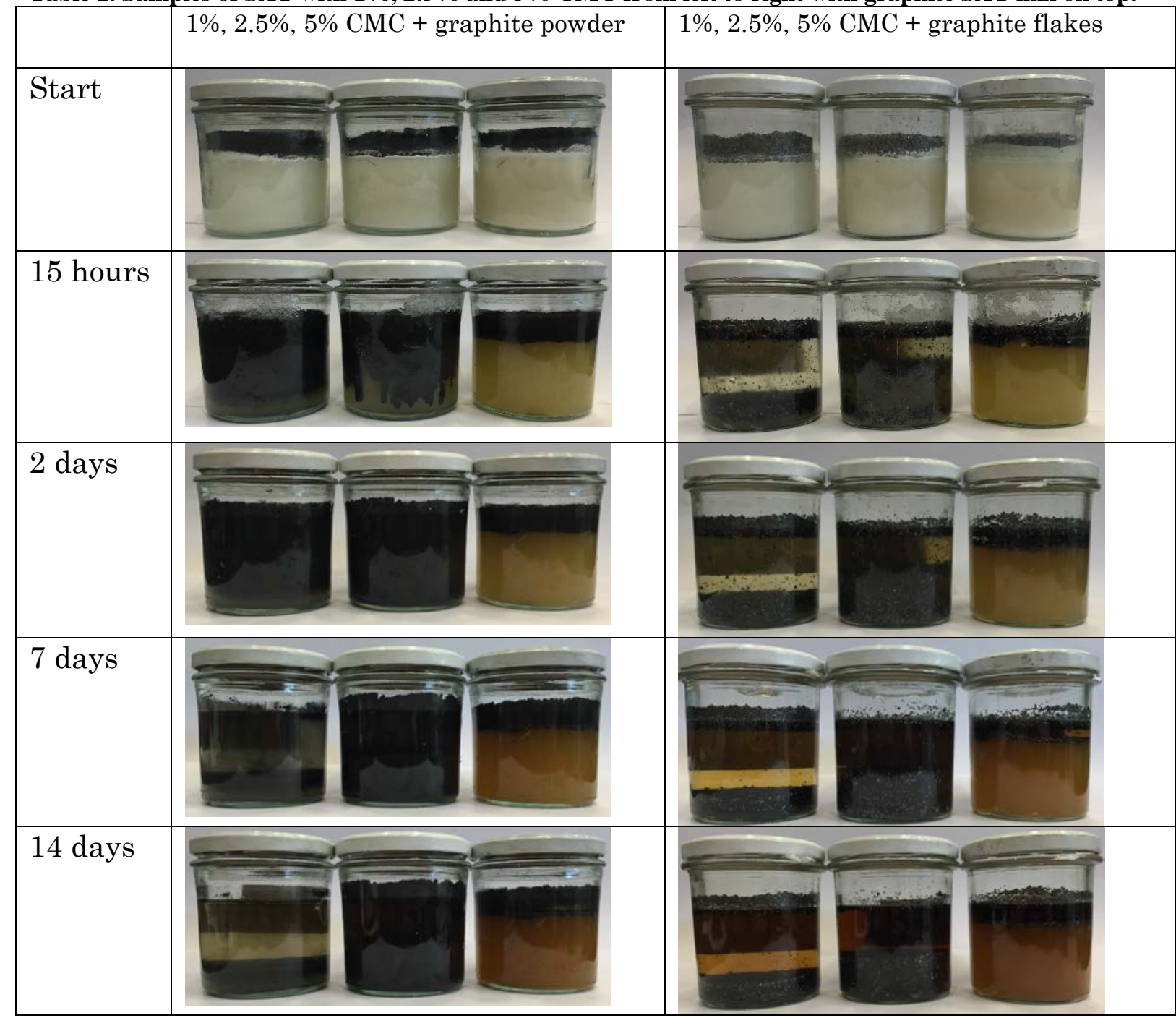

It is clear from the pictures in Table 1 that both the graphite powder and the graphite flakes started to settle to the bottom of the samples thickened with $1 \%$ and 2.5\% CMC after one day at $90{ }^{\circ} \mathrm{C}$. The graphite remained suspended on the top of the PCM composites with $5 \%$ CMC during the test period of 14 days. This indicates that to keep a uniform PCM composite where graphite particles stays suspended, the SAT needs to be thickened with at least 5\% CMC. From the pictures it can also be seen that the color of the PCM mixtures darkened over the heating period. This might indicate that the CMC breaks down over time and it could lose its thickening ability when applied at this temperature. A longer test period is needed to clarify this. 
Table 2. Samples of SAT with $0.25 \%, 0.5 \%$ and $1 \%$ xanthan rubber with graphite SAT mix on top.

\begin{tabular}{|c|c|c|}
\hline & $\begin{array}{l}0.25 \%, 0.5 \%, 1 \% \text { xanthan rubber } \\
+ \text { graphite powder }\end{array}$ & $\begin{array}{l}0.25 \%, 0.5 \%, 1 \% \text { xanthan rubber } \\
+ \text { graphite flakes }\end{array}$ \\
\hline start & & \\
\hline 15 hours & 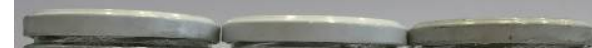 & $=$ \\
\hline 2 days & & \\
\hline 7 days & $=$ & 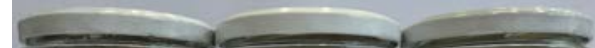 \\
\hline 14 days & 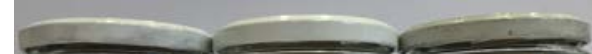 & $-1=$ \\
\hline
\end{tabular}

Inspection of the SAT samples thickened with xanthan rubber showed that after one day in the oven at $90{ }^{\circ} \mathrm{C}$ graphite flakes began to fall through the PCM composite with $0.25 \%$ and $0.5 \%$ xanthan rubber. In the sample with $0.25 \%$ xanthan rubber and graphite powder the layer of graphite started to segregate after 2 days and for the sample with $0.5 \%$ xanthan rubber slight segregation was observed after 7 days. The composite with $1 \%$ xanthan rubber maintained the graphite suspended on the top of the sample throughout the test period. Similarly to the composites with CMC, the color of the mixtures darkened over the heating period, which might indicate degradation of the xanthan rubber.

Although handling of the samples was done carefully, some shaking of the samples may have influenced the segregation of graphite. 


\subsection{Formation of cavities and thermal conductivity}

The solidification behaviors of the PCM samples were inspected visually at the cuts through the samples. Pictures of the layers of the PCM samples with the formed cavities can be seen in Table 3. Averaged values of the measurements of the thermal conductivity at different layers are also listed in Table 3.

Values in parentheses are measurement where the probe was placed on top of obvious cavities. Here the individual measurement varied with up to $\pm 0.15 \mathrm{~W} / \mathrm{m} \mathrm{K}$ depending on placement of the probe. Numbers listed without parentheses indicate a measuring point on an apparently solid surface, where the variations between measurements were $\pm 0.02 \mathrm{~W} / \mathrm{m} \mathrm{K}$. No measurements were made if there was a large cavity where the probe had to be placed. "NA" in the table is representing large cavities in the samples where no measurements were made.

Table 3. View of cavities and measured thermal conductivity in different layers of the SAT composites

\begin{tabular}{|c|c|c|c|c|}
\hline & Top & Upper & Lower & Bottom \\
\hline \multicolumn{5}{|c|}{ SAT Natural } \\
\hline & $(0.12 \mathrm{~W} / \mathrm{m} \mathrm{K})$ & $(0.07 \mathrm{~W} / \mathrm{m} \mathrm{K})$ & $0.68 \mathrm{~W} / \mathrm{m} \mathrm{K}$ & $0.67 \mathrm{~W} / \mathrm{m} \mathrm{K}$ \\
\hline \multicolumn{5}{|l|}{$\begin{array}{l}\text { SAT } \\
\text { Supercool }\end{array}$} \\
\hline & $0.38 \mathrm{~W} / \mathrm{m} \mathrm{K}$ & $0.31 \mathrm{~W} / \mathrm{m} \mathrm{K}$ & $0.59 \mathrm{~W} / \mathrm{m} \mathrm{K}$ & $0.56 \mathrm{~W} / \mathrm{m} \mathrm{K}$ \\
\hline \multicolumn{5}{|l|}{$\begin{array}{l}\text { SAT } \\
9 \% \text { extra } \\
\text { water } \\
\text { Natural }\end{array}$} \\
\hline & $\mathrm{NA}$ & NA & $\mathrm{NA}$ & $0.64 \mathrm{~W} / \mathrm{m} \mathrm{K}$ \\
\hline \multicolumn{5}{|l|}{$\begin{array}{l}\text { SAT } \\
9 \% \text { extra } \\
\text { water } \\
\text { Supercool }\end{array}$} \\
\hline & $0.53 \mathrm{~W} / \mathrm{m} \mathrm{K}$ & $0.46 \mathrm{~W} / \mathrm{m} \mathrm{K}$ & $0.59 \mathrm{~W} / \mathrm{m} \mathrm{K}$ & $0.65 \mathrm{~W} / \mathrm{m} \mathrm{K}$ \\
\hline
\end{tabular}




\begin{tabular}{|c|c|c|c|c|}
\hline \multirow[t]{2}{*}{$\begin{array}{l}\text { SAT } \\
1 \% \text { CMC } \\
\text { Natural }\end{array}$} & & & & \\
\hline & $(0.58 \mathrm{~W} / \mathrm{m} \mathrm{K})$ & $0.65 \mathrm{~W} / \mathrm{m} \mathrm{K}$ & $0.64 \mathrm{~W} / \mathrm{m} \mathrm{K}$ & $0.64 \mathrm{~W} / \mathrm{m} \mathrm{K}$ \\
\hline \multirow[t]{2}{*}{$\begin{array}{l}\text { SAT } \\
1 \% \text { CMC } \\
\text { Supercool }\end{array}$} & & & & \\
\hline & $0.59 \mathrm{~W} / \mathrm{m} \mathrm{K}$ & $(0.57 \mathrm{~W} / \mathrm{m} \mathrm{K})$ & $0.65 \mathrm{~W} / \mathrm{m} \mathrm{K}$ & $0.63 \mathrm{~W} / \mathrm{m} \mathrm{K}$ \\
\hline \multirow[t]{2}{*}{$\begin{array}{l}\text { SAT } \\
1 \% \text { CMC } \\
2 \% \text { graphite } \\
\text { powder } \\
\text { Natural }\end{array}$} & & & & \\
\hline & $(0.43 \mathrm{~W} / \mathrm{m} \mathrm{K})$ & NA & $(0.74 \mathrm{~W} / \mathrm{m} \mathrm{K})$ & $0.85 \mathrm{~W} / \mathrm{m} \mathrm{K}$ \\
\hline $\begin{array}{l}\text { SAT } \\
1 \% \text { CMC } \\
2 \% \text { graphite } \\
\text { powder } \\
\text { Supercool }\end{array}$ & & & & \\
\hline & $0.60 \mathrm{~W} / \mathrm{m} \mathrm{K}$ & $(0.45 \mathrm{~W} / \mathrm{m} \mathrm{K})$ & $0.83 \mathrm{~W} / \mathrm{m} \mathrm{K}$ & $0.84 \mathrm{~W} / \mathrm{m} \mathrm{K}$ \\
\hline \multirow[t]{2}{*}{$\begin{array}{l}\text { SAT } \\
0.5 \% \\
\text { xanthan } \\
\text { rubber } \\
\text { Natural }\end{array}$} & & & 4 & \\
\hline & $(0.50 \mathrm{~W} / \mathrm{m} \mathrm{K})$ & $(0.57 \mathrm{~W} / \mathrm{m} \mathrm{K})$ & $(0.54 \mathrm{~W} / \mathrm{m} \mathrm{K})$ & $0.65 \mathrm{~W} / \mathrm{m} \mathrm{K}$ \\
\hline \multirow[t]{2}{*}{$\begin{array}{l}\text { SAT } \\
0.5 \% \\
\text { xanthan } \\
\text { rubber } \\
\text { Supercool }\end{array}$} & & & & \\
\hline & $(0.52 \mathrm{~W} / \mathrm{m} \mathrm{K})$ & $(0.59 \mathrm{~W} / \mathrm{m} \mathrm{K})$ & $(0.57 \mathrm{~W} / \mathrm{m} \mathrm{K})$ & $0.59 \mathrm{~W} / \mathrm{m} \mathrm{K}$ \\
\hline $\begin{array}{l}\text { SAT } \\
0.5 \% \\
\text { xanthan } \\
\text { rubber } \\
5 \% \text { graphite }\end{array}$ & & & & \\
\hline
\end{tabular}




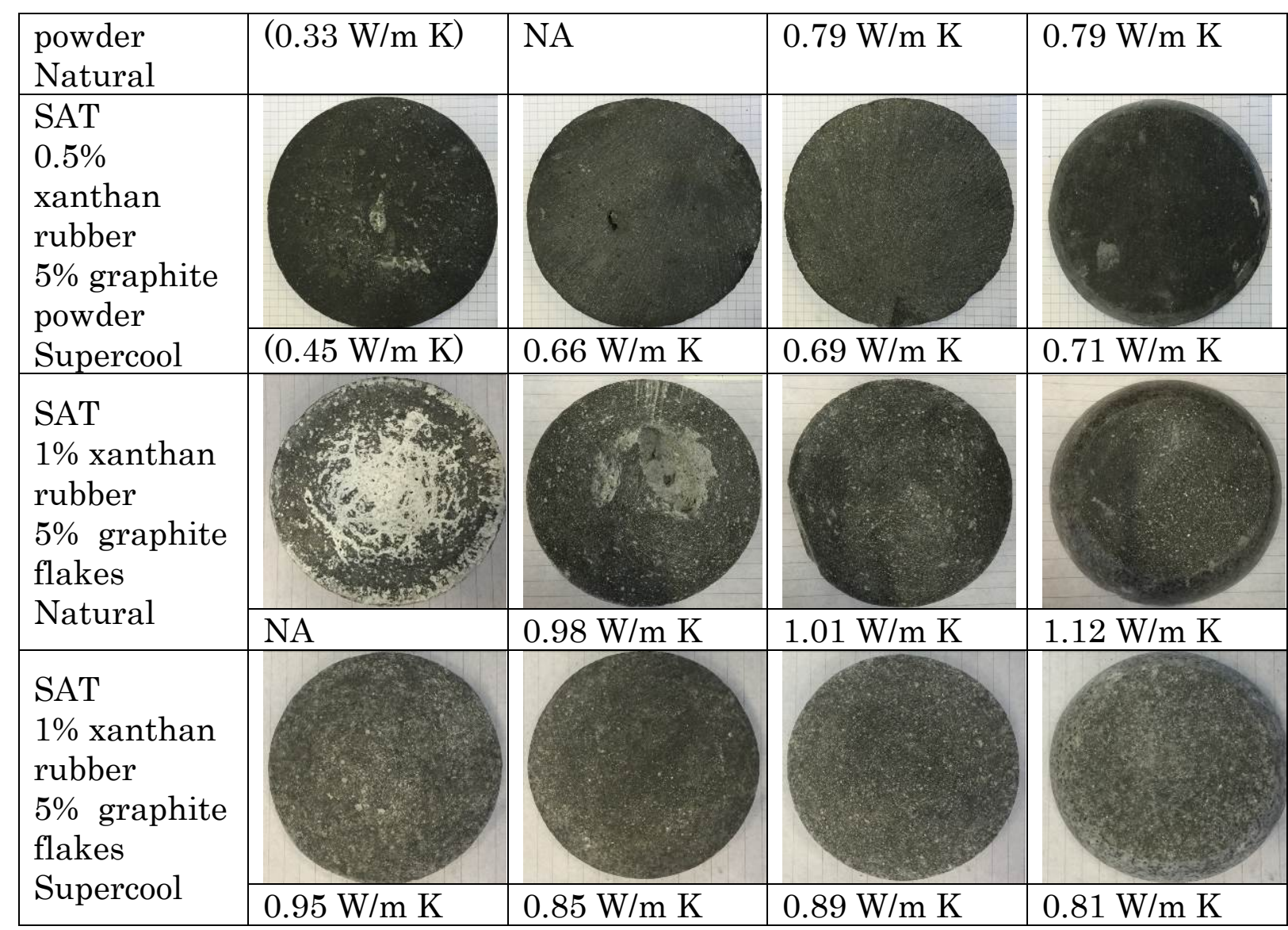

The samples of SAT without additives that crystalized during cooling down formed solid crystals in the bottom and near the sides of the glass jar and the cavities were concentrated in the upper central part of the sample. The sample of SAT without additives that crystalized from supercooled state formed a whiter softer crystal structure without large visual cavities, most likely due to the fast crystallization speed. The thermal conductivity of the lower and bottom layers representing the densest solid was significant lower in the sample that had solidified from the supercooled state compared to the sample that solidified without supercooling. The sample that crystalized with supercooling appeared with a more easily breakable crystal structure and a whiter color.

The supercooled SAT composite with 9\% extra water (consisting of $45 \%$ water and $55 \%$ Sodium acetate) was clearly moist. The extra water increased the thermal conductivity throughout the sample compared to the sample of SAT without extra water for the supercooled case. The sample with extra water which solidified during cooling down without supercooling pushed the extra water away from the crystallization front. This left a pool of saturated salt water solution in upper central part of the sample when ambient temperature was reached. In this case the measured thermal conductivity was similar to the sample without extra water in to bottom layer.

Solidified SAT samples that were thickened with CMC appeared to have one large star shaped cavity in the center of the sample with long straight partition lines splitting the sample. The lengths of the cavities were up to $90 \mathrm{~mm}$ long and $40 \mathrm{~mm}$ wide. The mixture with SAT and CMC that crystalized from supercooled state showed similar contraction and splitting behavior, but a smaller cavity was formed. The average thermal conductivity was slightly higher for the sample that had not been supercooled.

The samples that were thickened with xanthan rubber and solidified without supercooling formed multiple oblong cavities across the majority of the two middle layers except from very 
near the perimeter of the sample. The cavities were up to $40 \mathrm{~mm}$ long and $12 \mathrm{~mm}$ wide, most of the cavities were smaller. The sample thickened with xanthan rubber which crystalized after supercooling formed minor clustered cavities with diameters up to $3 \mathrm{~mm}$. Some circular cavities may be due to air bobbles trapped in the PCM mixture from the mixing process. The bottom layer of the samples with SAT, 1\% CMC and 2\% graphite powder had a thermal conductivity 31\% higher than of the sample with SAT and CMC. In the top surface of the sample the thermal conductivity was similar to that of the SAT sample with CMC. This indicates that the concentration of graphite powder may have been larger in the bottom of the sample in coherence with the findings in section 3.1.

Samples with SAT, $0.5 \%$ xanthan rubber and 5\% graphite powder had thermal conductivities 20\%-22\% higher than the sample with SAT and xanthan rubber. The cavities formed tended to be larger but fewer compared to the mixture of SAT and xanthan rubber without graphite. Only few obvious cavities can be observed in the supercooled sample of SAT and 0.5\% xanthan rubber and 5\% graphite powder. Consistently with the other findings, the crystals formed from solidifying without supercooling had higher thermal conductivity than from crystallization from supercooled state.

The solidification behavior and formation of cavities were similar for the composite with SAT, xanthan rubber and graphite flakes as for the sample with SAT, Xanthan rubber and graphite powder. Both samples consisted of $5 \%$ graphite, but the graphite flakes improved the thermal conductivity of up to $72 \%$ for the naturally cooled sample and $50 \%$ for the supercooled sample compared the sample with SAT and 0.5\% xanthan rubber. This can be explained by the larger graphite particles giving longer distances for the heat to conduct and fewer transitions between SAT and graphite.

The investigated samples underwent only one heating and cooling cycle. As phase separation might worsen over repeated cycles, it is expected that the composition in the layers of the SAT samples without thickening agents would change with repeated cycles. This may influence the thermal conductivity in the different layers. Phase separation is avoided and the suspension of graphite is sustained in the composites containing thickening agents, as long as sufficient thickening agent is added and it does not degrade. In this case, it is expected that the composition in the layers will remain constant over repeated heating and cooling cycles. Results from Table 1 indicated that the composites with 5\% CMC or 1\% xanthan rubber were stable for 14 days at $90^{\circ} \mathrm{C}$. Repeated heating and cooling cycles or heating periods longer than 14 days may destabilize the composite. Future cycling tests must clarify this. Considering solidification behavior and formation of cavities in repeated thermal cycles, it is suggested that in composites where the viscosity in the melted state is low enough to let air bobbles escape from the sample, there will be no difference in solidification behavior with repeated cycles. For composites with a high viscosity that may trap air bobbles in the PCM, an effect of increasing the air trapped inside the PCM may occur with repeated cycles, if new air is sucked into the PCM each time the PCM solidifies and contracts. Future cycling tests should elucidate this.

The measured values of thermal conductivity of samples mixed with graphite were significantly lower than what was found by Shin et al., who investigated a SAT composite with 2.5\% expanded graphite and 5\% CMC which had a thermal conductivity of $1.85 \mathrm{~W} / \mathrm{m} \mathrm{K}$ [21]. The difference could be due to better performance of EG compared to the graphite types used in this article.

As the samples cooled from the heated state to the ambient temperature, the heat flux was away from the center of the samples and through the outer surface. In the naturally cooled samples the first part of the samples to reach the crystallization temperature would be the PCM by the perimeter of the sample where the solidification would start. When the PCM crystalizes at a slow speed during cooling the formation of crystals has time to form dense 
crystals. When there is a contraction of the PCM as it crystalizes and the possibility for the liquid PCM to move/float, the cavities forming, due to the contraction, would appear in the central and upper part of the samples, where the temperature drops last. On the contrary, when a sample crystalizes with a high speed from a supercooled state, the PCM does not have time to contract and form a cavity in the center of the sample, but will create less dense crystals over the entire section and with smaller cavities or with no visual cavities at all. From a heat transfer point of view, the formation of the cavity in the center of the sample will give the best heat transfer ability as no heat stored in the cavity in the center has to be transferred away. Minor cavities spread out over the sample will give an insulating affect and there will be heat stored in the center which needs to be conducted longer distances compared to the samples with cavities in the center.

Considering actual applications, these investigations indicated whether a PCM storage operating with or without supercooling would affect the location of cavities formed due to contraction. Also the geometry of an actual storage including the heat exchanger design may influence the location of the cavities. In the cases where the contraction of the PCM causes a large central cavity and dense PCM near the heat transfer area, the insulating effect of the cavities may be minimal. In this case the values of thermal conductivity without parentheses listed in Table 3 could be averaged and used for calculations and simulation tools. In the cases where cavities are spread out or crystallization occurs from a supercooled state, the effective thermal conductivity of the bulk PCM is significantly lower than for dense PCM. In this case the thermal conductivity for the bulk PCM used for calculations and simulations tools can be approximated by the averages of the values in Table 3, with and without parentheses.

\section{CONCLUSIONS}

The suspension test with composites of SAT and different quantities of thickening agents showed that to keep graphite powder or graphite flakes suspended on top of the mixture, the SAT had to be thickened with at least 5\% CMC or 1\% xanthan rubber.

In SAT composites that solidified without supercooling, the contraction of the PCM during solidification caused formation of cavities in the central upper part of the samples. Samples that solidified from supercooled state formed smaller or no visual cavities. The type of thickening agent affected the solidification and the formation of the cavities. PCM mixtures thickened with Carboxymethyl cellulose formed one large cavity in the center of the sample, no matter if it was supercooled or not. The PCM composite thickened with Xanthan rubber that solidified without supercooling formed smaller cavities spread out in the entire volume of the sample except very close to the perimeter in the sample. PCM mixtures thickened with xanthan rubber has a risk of trapping air bobbles in the sample due to their jelly consistency even at temperatures up to $90^{\circ} \mathrm{C}$

The location of the cavities affected the measured thermal conductivity of the bulk PCM. The measured thermal conductivity was generally lower in the PCM composite that had solidified from a supercooled state compered to composites that had solidified without supercooling except for the sample with extra water.

The thermal conductivity was up to $0.68 \mathrm{~W} / \mathrm{m} \mathrm{K}$ in the areas without visual cavities in the SAT samples without graphite that crystalized without supercooling. In a PCM composite with SAT, $1 \%$ xanthan rubber and 5\% graphite flakes, the thermal conductivity was up to 1.1 W/m K.

\section{ACKNOWLEDGEMENT}


This research was funded by the Danish Energy Agency supporting the joint IEA SHC Task 42/ ECES Annex 29 programme on Compact Thermal Energy Storage.

\section{REFERENCES}

[1] B. Zalba, J.M. Marin, L.F. Cabeza, H. Mehling, Review on thermal energy storage with phase change: materials, heat transfer analysis and applications, Appl. Therm. Eng. 23 (2003) 251-283.

[2] A. Sharma, V. V Tyagi, C.R. Chen, D. Buddhi, Review on thermal energy storage with phase change materials and applications, Renew. Sustain. Energy Rev. 13 (2009) 318345. doi:10.1016/j.rser.2007.10.005.

[3] B. Sandnes, J. Rekstad, Supercooling salt hydrates: Stored enthalpy as a function of temperature, Sol. Energy. 80 (2006) 616-625. doi:10.1016/j.solener.2004.11.014.

[4] M. Dannemand, J.M. Schultz, J.B. Johansen, S. Furbo, Long term thermal energy storage with stable supercooled sodium acetate trihydrate, Appl. Therm. Eng. 91 (2015) 671-678. doi:10.1016/j.applthermaleng.2015.08.055.

[5] S. Jegadheeswaran, S.D. Pohekar, Performance enhancement in latent heat thermal storage system: A review, Renew. Sustain. Energy Rev. 13 (2009) 2225-2244. doi:10.1016/j.rser.2009.06.024.

[6] W. Li, J. Mao, L. Wang, L. Sui, Effect of the Additive on Thermal Conductivity of the Phase Change Material, Adv. Mater. Res. 399-401 (2011) 1302-1306. doi:10.4028/www.scientific.net/AMR.399-401.1302.

[7] S.-Y. Lee, H.K. Shin, M. Park, K.Y. Rhee, S.-J. Park, Thermal characterization of erythritol/expanded graphite composites for high thermal storage capacity, Carbon N. Y. 68 (2014) 67-72. doi:10.1016/j.carbon.2013.09.053.

[8] L.F. Cabeza, H. Mehling, S. Hiebler, F. Ziegler, Heat transfer enhancement in water when used as PCM in thermal energy storage, Appl. Therm. Eng. 22 (2002) 11411151. doi:10.1016/S1359-4311(02)00035-2.

[9] A. Sari, A. Karaipekli, Thermal conductivity and latent heat thermal energy storage characteristics of paraffin/expanded graphite composite as phase change material, Appl. Therm. Eng. 27 (2007) 1271-1277. doi:10.1016/j.applthermaleng.2006.11.004.

[10] A. Mills, M. Farid, J.R. Selman, S. Al-Hallaj, Thermal conductivity enhancement of phase change materials using a graphite matrix, Appl. Therm. Eng. 26 (2006) 1652- 
1661. doi:10.1016/j.applthermaleng.2005.11.022.

[11] X. Py, R. Olives, S. Mauran, Paraffin/porous-graphite-matrix composite as a high and constant power thermal storage material, Int. J. Heat Mass Transf. 44 (2001) 27272737. doi:10.1016/S0017-9310(00)00309-4.

[12] Z. Zhang, X. Fang, Study on paraffin/expanded graphite composite phase change thermal energy storage material, Energy Convers. Manag. 47 (2006) 303-310. doi:10.1016/j.enconman.2005.03.004.

[13] L. Fan, J.M. Khodadadi, Thermal conductivity enhancement of phase change materials for thermal energy storage: A review, Renew. Sustain. Energy Rev. 15 (2011) 24-46. doi:10.1016/j.rser.2010.08.007.

[14] T. Kousksou, P. Bruel, a. Jamil, T. El Rhafiki, Y. Zeraouli, Energy storage: Applications and challenges, Sol. Energy Mater. Sol. Cells. 120 (2014) 59-80. doi:10.1016/j.solmat.2013.08.015.

[15] J.B. Johansen, M. Dannemand, W. Kong, J. Fan, J. Dragsted, S. Furbo, Thermal Conductivity Enhancement of Sodium Acetate Trihydrate by Adding Graphite Powder and the Effect on Stability of Supercooling, Energy Procedia. 70 (2015) 249-256. doi:10.1016/j.egypro.2015.02.121.

[16] M.M. Farid, A.M. Khudhair, S.A.K. Razack, S. Al-Hallaj, A review on phase change energy storage: materials and applications, Energy Convers. Manag. 45 (2004) 15971615. doi:10.1016/j.enconman.2003.09.015.

[17] S. Furbo, Investigations of Heat Storages with salt hydrate as storage medium based on the extra water principle, Therm. Insul. Labotatory, DTU, Kgs. Lyngby, Denmark, Rep. 80. Meddelelse (1978).

[18] B.M.L. Garay Ramirez, C. Glorieux, E.S. Martin Martinez, J.J. a Flores Cuautle, Tuning of thermal properties of sodium acetate trihydrate by blending with polymer and silver nanoparticles, Appl. Therm. Eng. 61 (2013) 838-844. doi:10.1016/j.applthermaleng.2013.09.049.

[19] P. Hu, D.-J. Lu, X.-Y. Fan, X. Zhou, Z.-S. Chen, Phase change performance of sodium acetate trihydrate with AIN nanoparticles and CMC., Sol. Energy Mater. Sol. Cells. 95 (2011) 2645-2649. doi:10.1016/j.solmat.2011.05.025.

[20] H.W. Ryu, S.W. Woo, B.C. Shin, S.D. Kim, Prevention of supercooling and stabilization of inorganic salt hydrates as latent heat storage materials, Sol. Energy Mater. Sol. Cells. 27 (1992) 161-172. doi:10.1016/0927-0248(92)90117-8. 
[21] H.K. Shin, M. Park, H.-Y. Kim, S.-J. Park, Thermal property and latent heat energy storage behavior of sodium acetate trihydrate composites containing expanded graphite and carboxymethyl cellulose for phase change materials, Appl. Therm. Eng. 75 (2015) 978-983. doi:10.1016/j.applthermaleng.2014.10.035.

[22] K.K. Meisingset, F. Grønvold, Thermodynamic properties and phase transitions of salt hydrates between 270 and $400 \mathrm{~K}$ III. CH3CO2Na·3H2O, CH3CO2Li·2H2O, and (CH3CO2)2Mg•4H2O, J. Chem. Thermodyn. 16 (1984) 523-536. doi:10.1016/00219614(84)90003-X.

[23] G. Lane, Solar heat storage latent heat material Vol 2, CRC, Boca Raton, Florida, United states, 1986.

[24] N. Shamsundar, Similarity Rule for Solidification Heat Transfer with Change in Volume, J. Heat Transfer. 103 (1981) 173-175.

[25] J.C. Choi, S.D. Kim, G.Y. Han, Heat transfer characteristics in low-temperature latent heat storage using salt-hyrate, Sol. Energy Mater. Sol. Cells. 40 (1996) 71-87.

[26] L. Dietz, J.S. Brukner, C.A. Hollingsworth, LINEAR CRYSTALLIZATION VELOCITIES OF SODIUM ACETATE IN SUPERSATURALTED SOLUTIONS, 61 (1951) 944-948.

[27] A. Fopah Lele, K.E. N'Tsoukpoe, T. Osterland, F. Kuznik, W.K.L. Ruck, Thermal conductivity measurement of thermochemical storage materials, Appl. Therm. Eng. 89 (2015) 916-926. doi:10.1016/j.applthermaleng.2015.06.077.

[28] T. Inagaki, T. Isshiki, Thermal Conductivity and Specific Heat of Phase Change Latent Heat Storage Material Sodium Acetate Trihydrate and Heat Transfer of Natural Convection in a Horizontal Enclosed Rectangular Container, Kagaku Kogaku Ronbunshu. 39 (2013) 33-39. doi:10.1252/kakoronbunshu.39.33.

[29] N. Araki, M. Futamura, A. Makino, H. Shibata, Measurements of Thermophysical Properties of Sodium Acetate Hydrate, Internaltional J. Thermophys. 16 (1995) 14551466.

[30] User’s guide ISOMET Heat Transfer Analyser model 2104, (n.d.). 